by several different individuals entirely independent from one another, and more and more frequently it is only chance that determines the passionately controversial matter of "who was first" (the only goal that comes into consideration). The historians and others like them will be rather cool toward Ostwald's somewhat naive phillistinism, which is just how they must receive his work. But, e.g., Rickert, at any rate, could hardly have wished for a better paradigm of specifically "natural scientific" thinking (in a logical sense).

Enough! Even through the incorporation of the psychical in to the energetic dreadfully little would be established for a "foundations of the cultural sciences" (in Ostwald's sense). Admittedly, Ostwald only suggests the possibility of such an incorporation of the psychical into the energetic in this book (70), while on the other hand he also again emphasizes that the limits of his inquiry lie precisely at that point where "psychological" factors become involved. But how should this incorporation be carried out? I have sought elsewhere in connection with the work of Kraeplin and others to bring home to the readers of the Archivs fur Socialwissenschaft as well as a layman can, just how infinitely complicated, "energetically" considered, the intricate play of the "psychical" upon the "psycho-physics" of work takes shape. But Ostwald obviously does not have this aspect of the psycho-physical problem in mind. However, should he have something like Wundt's doctrine of the "law of the increase of psychical energy" in view, which has already been disposed of scientifically, and which confusedly conflates the "increase" of that which we call the "intellectual content" of a culturally relevant process (hence an evaluative designation) with the category of psychical existence, then the mischief that Lamprecht has caused with this confusion must be a warning to us. It is also worth noting that the Freudian doctrines, which seemed to ordain a kind of "law of the preservation of psychical (affect)-energy" in their first formulation, have in the meantime been reformulated by their own author in such a way that they have lost every bit of rigour in an "energetic" sense (which might even have consequences for their psychopathological value). At least the strict energeticist will at any rate no longer find them of any use. They would, of course, naturally in no case provide a legitimation for getting rid of all those approaches of the "sciences of culture" that might serve as a common denominator to the benefit of any sort of "psychology" but that were not comprehensible for "energetics"-just in case, given their peculiarity, they should ever be able to do this. But, again, enough of all this. For us the point was to determine in general the place where methodologically the author overstepped the region where his point of view has theoretical validity (we have already considered practical issues).

\section{EPISTEMOLOGY, AXIOLOGY, AND IDEOLOGY IN SOCIOLOGY*}

Michael R. Hill

University of Nebraska-Lincoln

Mid-American Review of Sociology, 1984, Vol. IX, No. 2:59-77

\section{INTRODUCTION}

This paper (a) presents a systems framework for conceptualizing epistemological issues in sociology, (b) links this framework to axiological responsibilities, and then (c) locates both the epistemological and axiological discussions within the patriarchal ideology and hierarchical power structure of American sociology. It is argued that adopting an activist, emancipatory ideological position obligates social scientists to critically review their axiological commitments and epistemological premises. Major arguments are set in italics to permit a quick scan of the paper. These arguments form an epistemological position paper for the closing of the Twentieth Century.

\section{THE EPISTEMOLOGICAL ARGUMENT}

The several philosophical, methodological, and theoretical perspectives in sociology are here conceived as knowledge-producing systems.

The concept of "knowledge-producing system" adopted here is an analytical framework for thinking about the various sociological perspectives. The framework is adapted from Radnitzky (1973) who applies system-theoretic concepts to investigate differing styles of scientific thought. He conceives of "science" as essentially "a knowledge-producing and knowledge-improving enterprise." Each such enterprise is conceptualized as a "system" composed of a set of interrelated elements.

The terms "positivism," "empiricism," "Marxism," "structuralism," "feminism," "hermeneutics," "existentialism," "idealism," "pragmatism," "phenomenology," "dramaturgy," "symbolism," and

*An abbreviated version of this paper was presented at the Annual Meetings of the Midwest Sociological Society, Chicago, Illinois, April 18-21, 1984. 
so forth are markers identifying major orientations in sociology. These differing perspectives are "knowledge-producing systems" which can be identified, examined, and discussed. Further, each knowledgeproducing system can be assessed in terms of its effectiveness (either demonstrated or potential) in accomplishing various social projects. This schema goes a reasonable distance in clarifying the epistemological, axiological, and political debates which so often cloud the sociological horizon.

There is no limit on the number of systems which may be invented or proposed.

No a priori limit can be placed on the number of knowledgeproducing systems which may be introduced for discussion and utilization in sociology. It is dichotomizing persiflage to suggest that only one epistemological conceptualization of sociology is legitimate while all others are illegitimate. To so suggest is a premature blunder which not only tosses out charlatans, but also dismisses serious, creative thinkers in the same throw. The intellectual errors arising from hastily structuring epistemological debates on dichotomous lines (e.g., "science" vs. "non-science") are divisive, unproductive, and unnecessary.

It is understandable that those who cut their sociological teeth as positivists are not accustomed to especially wide interpretations of "science." The positivist tradition has been so overwhelmingly accepted in North America that any other perspective is necessarily regarded as "unscientific." This massive acceptance of the positivist model is the root cause of whatever "strangeness" may be felt to lie with the assertion that alternative, non-positivist viewpoints in sociology today also claim the "scientific" label with equal rationale.

Phenomenology, for example, makes "scientific" claims. One of Husserl's main objectives was to establish science on what he believed to be a foundation more solid than that on which positivism has been erected. We are reminded that throughout his work, "Husserl's commitment to the ideal of a rigorous science never wavered" (Spiegelberg, 1971:77, emphasis added). Amedeo Giorgi echoed Husserl's foundational theme in his attempt to establish phenomenological psychology:

Through a utilization of the philosophical tenets of existential phenomenology, we are attempting to found psychology conceived as a human science (Giorgi et al., 1971 :xi, emphasis added).
Phenomenologists turn specifically toward the study of man and assert that human science should be grounded on philosophical roots rather different from those embraced by logical positivists.

Structuralists provide a further exemplar. It is fully reasonable to consider structuralists "scientific" inasmuch as they are committed to intellectual rigor and have contributed much to linguistics, cybernetics, and our understanding of logic. Yet, like the phenomenologists, they have been extremely critical of logical positivism. An example is a paper by Emmon Bach (1965):

... which for all its courtesy and fairness, is a severe critique of logical positivism and the linguistic methods it inspired (Piaget, 1970:83).

Such examples can be presented many times over. The point is that there are many alternative viewpoints in sociology which consider themselves to be both "scientific" and non-positivist.

Nontheless, there are several sociologists who eschew the term "science" although it would be entirely reasonable on various philosophical grounds to characterize them as "scientists." Their rejection of "science" does not signal their abandonment of intellectual rigor, but rather their rejection of the political connotations attached to "science" in a society wholly permeated by the positivist conception of "science." As a remedy, this paper adopts the label "knowledgeproducing system" to identify all perspectives, viewpoints, or paradigms in the social sciences without too early pre-judging whether a given perspective is scientific, scientistic, or merely stupid.

Each system is composed of three major elements: (a) metascientific worldviews, (b) methodologies, and (c) theories.

Knowledge-producing systems have three basic components: metascientific worldviews, methodologies and theories. These elements are interrelated such that input through any one element has the potential to affect the other components of the system. Although these systems may incorporate various contradictions, they strain toward logical consistency. This tendency is introduced by the builders and users of the systems. Before discussing these features of knowledgeproducing systems, each component part is introduced. 
Mid-American Review of Sociology

Metascientific Worldviews: The metascientific worldview of each perspective provides the background or tradition in which specific theories and methodologies are developed and evaluated. It includes the philosophical groundplan, beliefs, traditions, values, logic, and evaluative criteria of a given perspective.

In its philosophically programmatic aspects, each sociological perspective contains an identifiable metascientific worldview. This conception of "metascientific worldview" is more inclusive than Radnitzky's (1973) general scheme in that "philosophical groundplan" and "metascience" have been combined into a single element here called the "metascientific worldview." It is less inclusive than Leinfellner's (1974) concept of "epitheory" which gives primary attention to the "norms, values, and obligations" implied in a given theory and systematically delivers:

. . . the background knowledge into which a social theory is embedded and without which we may not fully understand such a theory. It constructs step by step the whole cultural and social superstructure or background knowledge (Leinfellner, 1974:40, emphasis added).

The framework proposed here is in sympathy with Leinfellner's wider aim, but, for the purposes of initial analysis, is restricted to the scientific community with which a particular perspective is associated. Axiological analysis of each knowledge-producing system necessitates reference to the larger societal and cultural values in which each system is embedded, but the specifically epistemological task is simplified if a less inclusive circle is drawn around the various viewpoints in sociology. The proposed definition of "metascientific worldview" is also similar in many respects to Thomas Kuhn's (1970) first (as opposed to his more specific and second) use of the term "paradigm." He suggests that "paradigm" may be used to stand:

... for the entire constellation of beliefs, values, techniques, and so on shared by the members of a given community (Kuhn, 1970:175).

The present framework is not at odds with this definition of "paradigm." Rather, it includes specific knowledge claims under the term "theory" and data collection techniques under the term "methodology."
Epistemology, Axiology, and Ideology

Methodologies: Methodologies are procedural rules which guide researchers in the active exploration of selected dimensions of social behavior and experience.

These rules are rooted in and are compatible with the metascientific worldview of the researcher. The "discoveries," "reports," or "findings" which result from the application of these rules form the "contents" which are the object of theoretical organization.

Theories: Theories are content-oriented conceptual frameworks formulated under the auspices of given metascientific worldviews. They are organizing devices which reveal or assert that selected dimensions of social behavior or experience are related in particular ways.

The organizational logic of theories and the dimensions of social behavior or experience selected for theoretical attention are influenced by the metascientific worldview to which a given theory-builder subscribes. It is through the use of theories that sociologists claim to present understanding or knowledge of the nature of society in general and human behavior or experience in particular.

This definition of "theory" is more general than that accepted under logical positivism (Hill, 1981). For the positivist, a "theory" is an axiomatized, deductively interconnected system of axioms, theorems, and definitions. At the same time, the definition proposed here is less general than that suggested by Amedeo Giorgi (1975), a phenomenologist:

Theory is somettmes used in the sense of a perspective or viewpoint. In that sense, phenomenology is a theory of science, of man, of the world in the sense that it attempts a coherent description and interpretation of all phenomena that can be experienced by man, but it also recognizes that it is but one among many such viewpoints or perspectives and it does not consider itself to be a dogmatic source of knowledge that cannot be challenged (Giorgi, 1975, personal communication).

Giorgi's use of theory overlaps with the above definition of metascientific worldview insofar as he calls a theory a "viewpoint" or "perspective." Still, he gives emphasis to coherent description and in this sense his conceptualization is compatible with the ideas expressed in the definition of theory offered in this paper. 


\section{Mid-American Review of Sociology}

The elements in each system are interdependent.

Each alternative perspective in sociology is a "system" with interdependent elements. Radnitzky (1973) summarized the nature of this interdependence when he asserted that the following observation is justified:

The active researcher cannot avoid to apply theories and to adopt, explicitly or implicitly some theoretical position. The theory-builder cannot avoid to adopt some metascientific position, e.g., in connection with the appraisal of competing knowledge systems, explanatory patterns, etc. The metascientific position in turn will be anchored in some philosophical groundplan, even if the latter is not articulated (Radnitzky, 1973:xii-xiii).

Even if it is not articulated, the philosophical groundplan embedded in the metascientific worldview influences metascientific logic, theory construction, and theory-guided methodological activity.

Each system attempts to maintain consistency among its elements according to its own rules of organization and logic.

The elements in each system are interdependent in a logically consistent manner. The nature of this "logic" is internally defined for each system. This strain for consistency is a fundamental characteristic of sociological enterprises whether they claim the label of "science" or not.

Strain on the internal consistency of a system may be introduced through any of the system's elements. Logically consistent inputs are accommodated without producing strain within the system. However, inputs which are incompatible with the overall logical consistency of the system are handled in either one of two ways: (1) First, and most likely, the incompatible inputs will be rejected so that the overall logical consistency of the system can be maintained. Thus, discoveries which cannot be theoretically organized, given the logic of the metascientific worldview, will be labelled "not relevant" or "errors." (2) Second, in unusually compelling situations, the inputs may be accepted and thus produce strain within the system. This may happen when "errors" and "anomalies" persist and become troublesome. Kuhn (1970) refers to such situations as "crises."
Epistemology, Axiology, and Ideology

According to Kuhn, a crisis often provides the motive force required to produce a scientific revolution in which an old paradigm is shelved in favor of a new framework which explains or takes care of the "anomalies." A system in crisis breaks down and is beyond repair. In less catastrophic situations, however, the acceptance of strain within the system may result in a stress reducing re-ordering of the entire system with a view toward re-establishing the overall consistency of the system by requiring sub-revolutionary changes in each of the system's interrelated elements.

Each system is epistemologically accountable only to its own rules of organization and logic.

The logic of each system is internal and cannot be fruitfully judged on external epistemological grounds. Each system has its own rules of logic and criteria for deciding when it has produced or improved "knowledge." This position does not, however, argue for state of intellectual anarchy in which "anything goes."

It is a fully proper epistemological task to question the internal consistency of a given perspective. But, this inquiry must be accomplished on the perspective's home turf. If analysis reveals serious internal contradictions or intellectual lacunae, the critic is obligated to present them and the relevant theorists must get busy with the needed repairs, if repairs are possible.

Responsible epistemological allegiance to a system requires its adherents to (a) fully articulate the elements in their system, (b) examine the system for internal inconsistencies, (c) propose remedies for inconsistencies when they are discovered, and (d) clearly identify and publicize any inconsistencies which prove unresponsive to diligent remedial efforts.

It is possible and responsible to ask the proponents of a given perspective to articulate their system, to explicate the rules of logic they apply, and to demonstrate that their perspective hangs together according to the rules of logic which they have themselves selected. The critic, however, must also demand the same analysis of the perspective to which he/she gives allegiance. The call for reciprocal and reflexive investigations of one's adopted knowledge-producing system lies at the heart of epistemological responsibility. 
Epistemological investigation may frequently require the excavation and reconstruction of "missing elements" in knowledge-producing systems.

Critics or proponents who attempt to outline a given sociological perspective may encounter the problem that the system's founders did not carefully articulate all of the elements in their system. Radnitzky indicated above that the elements are not always clearly explicated or understood by the researchers who adhere to a particular perspective. Some of the elements may be "missing." These must be excavated and reconstructed if the knowledge-producing system is to be seen as a whole.

Piaget's structuralism provides an example of the need for epistemological reconstruction. Piaget (1970:126) asserted that "structuralism cannot be a particular doctrine or philosophy" and, further, that "structuralism is essentially a method." What is "missing" in this example is the clear articulation of a metascientific worldview.

The guiding rule for reconstruction is the principle that the reconstructed metascientific worldview must be logically consistent with the theoretical and methodological elements in the system. The logical system itself must be inferred from the manner in which perspectival advocates utilize and construct their methodologies and theories. The critic as well as the proponent who would understand any perspectival viewpoint in contemporary sociology should be prepared to engage deeply and seriously in the archaeology and reconstruction of theories, methodologies, and metascientific worldviews.

\section{THE AXIOLOGICAL ARGUMENT}

Values are foundational for both knowledge-producing systems and social projects.

Values are embedded in the metascientific worldviews of sociological perspectives. There are no presuppositionless perspectives in the philosophical spectrum from phenomenology to positivism (cf., Eckhardt, 1973; Friedrichs, 1973). Values are incorporated as presuppositions in philosophical arguments which form the highest level in the hierarchical structure of scientific languages (Madsen, 1970). There are no value-free sociologies.

However, the values incorporated within sociological perspectives form only one side of the axiological problem facing sociologists.
Values also come into play in selecting the social projects which we address from a given perspectival viewpoint. Values are superordinate to both purpose and perspective.

Not all knowledge-producing systems are equally well-suited for every social project.

The range of possible social projects is limited only by the imagination. A few possibilities include: prediction, control, understanding, explanation, risk reduction, emancipation, production, distribution, justice, efficiency, equality, revolution, stability, innovation, anarchy, progress, enrichment, and so forth. No knowledge-producing system is well-suited to all projects.

It would be difficult to find a phenomenologist, for example, who would argue that phenomenology is well-equipped for the pursuit of "prediction," "control," and "efficiency." At the same time, most phenomenologists agree that "understanding" can be realized through the application of phenomenology. Similar reviews are possible for the other prespectival viewpoints in sociology.

The difficulty of such review, however, increases with the extent to which proponents of various perspectives have failed to thoroughly excavate and articulate the metascientific worldviews of the systems to which they subscribe. Such failure raises the possibility of axiological schizophrenia. Without an understanding of the values embedded in their metascientific worldviews, researchers run the risk of pursuing social projects with knowledge-producing systems ill-suited to selected tasks.

Not all social projects embody the highest axiological principles of human rights and dignity.

Matching a specific social project to an effective knowledgeproducing system is primarily an epistemological problem. On the other hand, deciding which social projects to pursue is a fundamentally axiological issue. Axiological analyses argue that some social projects are more defensible than others. It is one purpose of axiological analyses (e.g., Buttimer, 1974; Caws, 1967; Eckhardt, 1973; Hill, 1977; Leinfellner, 1973) to help society identify those projects which embody the highest principles of human rights and dignity.

Responsible axiological allegiance to a social project requires that its supporters (a) demonstrate (through research, reflexive study, and 
group dialogue) that the project embodies the highest axiological principles, (b) seek (or develop) an axiologically compatible knowledgeproducing system to assist in realizing the project, and (c) abandon the project if it no longer serves the highest axiological principles.

Existentially, accountability may be seen as an individual responsibility. Yet, group discussion of the issues involved in value-grounded decisions may help many of us begin the personal examination of the value foundations which underlie our teaching and research as well as our selection and endorsement of various social projects. Initiation of group dialogue is the responsibility of every social scientist who admits that discussion of value orientation is needed and reasonable. It has also been argued (Held, 1970) that members of a group can be held morally responsible if they fail to organize themselves (at least loosely) in order to discuss the most appropriate bases for decision when they find their community or society to be in a period of imminent danger, uncertainty, or crisis.

Honestly entertained, the effort to understand the value viewpoints of others results in a clearer understanding of one's own values. The reflexive nature of this effort opens one's own views to change and reformulation (Floistad, 1973). Dialogue enables individuals to make their axiological positions explicit.

Responsible axiological allegiance to a knowledge-producing system requires its adherents to (a) articulate the specific ways in which it is actually capable of realizing identified social projects, (b) routinely examine this statement for the possibility of false or over-zealous claims, (c) withdraw unsupported claims as soon as they are discovered, and (d) abandon the system if it no longer supports social projects to which they are responsibly committed.

It is axiologically proper and responsible to ask perspectival advocates to identify the social projects which they believe their perspective able to address. Advocates have a responsibility to demonstrate the success or likelihood of their adopted system. Quite possibly, many perspectival advocates who attempt this demonstration will find themselves embarassingly empty-handed.

Responsible social scientists must search for and support those social projects which embody the highest axiological principles.

Social projects which oppress, disenfranchise, or denigrate fellow humans cannot be legitimately supported by social scientists. This declaration is repeated, albeit somewhat embyronically, in the professional ethics code of the American Sociological Association (cf., Reynolds, 1983:143-169). We have sensed, as a group, the moral necessity to consider the rights of research subjects. The next, as yet untaken, step is to examine the rights not just of research subjects but of all persons who may be helped or hurt through our acts as data collectors, methodologists, social analysts, and theoreticians. In framing and undertaking these activities, can we do less than seek realization of social projects which incorporate the highest possible axiological principles?

Identification of the highest axiological principles is not easy, but this does not mean that this task can be responsibly avoided.

Axiological analysis has not been required in the sociological curriculum. Perhaps for this reason many of us face discussions of "values" with knots in our stomachs. We often do not know how to proceed. We are on unfamiliar ground. Perhaps some of us fear attacks on our motivations and personal integrity.

Axiological analysis is not easy. As in philosophy generally, there are various axiological schools of thought. One must read, study, and evaluate these ideas just as carefully as many of us concentrate on the intricacies of sophisticated statistical techniques.

The difficulty of value analysis does not relieve us of the obligation to begin. At the least, we can heed the advice to find and follow:

$$
\begin{aligned}
& \text {... a good person, or at least someone who is making the effort, at } \\
& \text { this particular time, to be good, to discover what it would be to do } \\
& \text { the right thing (Machan, 1974:368). }
\end{aligned}
$$

Obviously, we can and will make axiological mistakes. We may be deceived and follow the wrong lead. This is nothing new. As social analysts and theorists, we make methodological and conceptual mistakes all the time and we also make every effort to correct our errors and learn from our mistakes. It is time we invest the same effort in learning from our axiological failures.

We are responsible for the axiological shape of the future.

Values are intimately bound up in decisions concerning the route we will take toward the realization of the future. Caws (1967:54) astutely defined values as future facts: 
Mid-American Review of Sociology

... they go from us to the world; they refer not to what is or was the case, but to what will or may be the case.

Genuine values cannot be sought in the status quo although they helped form it. Values are realized through the active choice of alternative future facts. The responsibility which hangs heavily over us is to seek a personal and disciplinary understanding of the base on which we are willing to be held accountable for such decisions. It helps little to issue a liberal manifesto listing desirable social projects and then turn around and adopt sociological perspectives which insure that such projects are never realized.

\section{THE IDEOLOGICAL ARGUMENT}

Epistemological explication and axiological clarification are set within ideological environments.

Discussions of epistemology and values do not occur in abstract isolation. They are embedded in real societies, in specific institutions, and in particular historical circumstances. These societies, institutions, and times are permeated with special interests and legitimations for these interests. The stage for discussion is set within an ideological arena.

The ideological setting of sociology is repressively dominated by patriarchal worldviews and hierarchical power structures.

American sociology is centered in a hierarchically structured institution: American higher education. Power within this structure generally flows from the top down: trustees to presidents to deans to chairs to full professors to associate professors to assistant professors to instructors to graduate teaching assistants to undergraduate students. Academia is further dominated by patriarchy, classism, and racism (cf., Creutz, 1981; Hill, 1983; Maglin, 1982; Menges and Exum, 1983; Newman, 1982; and Parenti, 1980). Not unexpectedly, these patterns of domination are replicated in the discipline of sociology (cf., Deegan, 1980, 1981).

Responsible epistemological investigation and axiological discussions are fully possible only in settings characterized by emancipatory ideologies.
Epistemology, Axiology, and Ideology

Although explorations of values and epistemology are set within ideological contexts, some environments are more emancipatory than others. If the setting is not emancipatory, the debates within it are structured and permeated by the ideologies of anti-emancipatory interests. Such debates are designed to reproduce and extend institutional patterns which advance the interests of power elites. The outcome of epistemological/axiological dialogue in such settings is ideological debate rather than responsible, emancipatory discussion.

Epistemological/axiological debates within sociology are not essentially emancipatory, but instead serve patriarchal and hierarchically-structured interests in the academy and in society at large.

Mirroring the ideological context of the American academy, epistemological/axiological discussion within sociology frequently takes the form of destructive, dichotomous debates. The dichotomies are often exceptionally crude. Familiar oppositions include: "unscientific" vs. "scientific"; idiographic vs. nomothetic; qualitative vs. quantitative; contemporary vs. traditional; micro vs. macro; philosophical vs. empirical; ideological vs. value-free; applied vs. theoretical; and so forth. By concentrating on superficial characteristics which obscure intellectual substance, debates between dichotomized opponents generally destroy any potential for meaningful, emancipatory discovery. Deegan (1980:2) underscores this point: "We see that the themes of dichotomous thinking and elite control are common threads in patriarchal sociology." Dichotomous debates serve the interests of the status quo and must be analyzed politically rather than epistemologically.

Analysis of four variations on dichotomous epistemological-axiological debates in sociology illustrate the discipline's current state of moral poverty and intellectual aridity.

Combatants in disciplinary debates over the "correct" sociological perspective have vigorously pursued the elusive tasks of defining the nature of sociology, explicating the meaning of "truth," and legislating the procedures of methodology. Because of the repressive ideoolgical context of these debates, however, they are framed and structured for the purpose of avoiding the serious axiological questions and epistemological problems which should be central. It is instructive to review the common strategies which so often defeat constructive perspectival analyses in sociology. 
The "Synthesis" Move.

A synthesis is often little more than a superficial "I'm OK, You're OK" agreement accompanied by a series of hearty handshakes and approving smiles. In departments ripped apart by ongoing "theory wars," synthesis resolutions have considerable practical value. They allow academia to "get back to business as usual" while temporarily burying the proverbial hatchet and avoiding deep critiques. The "best of both worlds synthesis" is soothingly political rather than intellectually engaging.

The handshakes acknowledge that the more powerful faction is not fully able to censure its adversaries. Thus, a "synthesis" is proposed in the interim while the various factions re-group and bide their time. Neither side gives up its core arguments in a "synthesis." Each side simply points out that its perspective can profitably "inform" the other.

In the so-called "quantitative/qualitative" debate, for example, it is common for social science departments to enter into "synthesis" agreements in which the legitimacy of a given methodology rests partially on its presumed ability to inform the work of another perspective. In practice, particularly in departments where the quantitative model is highly valued, this means that qualitative work is "tolerated" for its ability to generate "hypotheses" which can later be studied quantitatively, i.e., "scientifically." It matters little that this is not what most advocates of qualitative research understand as the fruit of their efforts. In terms of course requirements, a "synthesis" agreement means that all qualitatively-oriented students are required to complete courses in statistics and measurement theory, but not necessarily vice versa. Quantitatively-oriented students are rarely required to complete a qualitative methods sequence. Such one-sided requirements are evidence of the political nature of a given "synthesis" agreement.

A one-sided "synthesis" is essentially a rhetoric which permits the less powerful, but unbeaten, faction to limp along while saving face. The political consequences for students are not small when a politicallymotivated "synthesis" is arranged. Due to the rhetoric of "synthesis," students attracted to the perspective of the less powerful faction may mistakenly assume that their interests and methodological inclinations are valued equally with those of the "mainstream" students. It is only later that such students realize they have been working under a serious handicap, that they will have to do much more work on their own than other students, that they will not have the intellectual support of the majority faculty, and that their work will be judged "marginal" by those who control access to funding and other discipline-linked perquisites.

Perspectives which are not party to a "synthesis" agreement (due, for example, to their being unrepresented by current faculty members) still suffer ridicule, misunderstanding, and lack of support. Usually only two, dichotomous views are presented. There is rarely provision for perspectives not represented by members of the current faculty. At best, "synthesis" outcomes are intellectually narrow. At worst, the outcome is political rhetoric disguised as philosophical dialectic.

The "Merely Political" Move.

Assertion that perspectival differences are merely political rather than "real" may sometimes be more honest but runs the risk of dismissing genuine intellectual disagreements without reflexive consideration of the issues involved. What the "merely political" and the "synthesis" arguments demonstrate, however, is the exceptional extent to which presumably intellectual arguments involve political issues, whether overt or implied. The charge that one is "merely playing politics" is a move which pre-empts all subsequent intellectual rationalizations that one can offer. Marxist and feminist scholars, for example, are frequently accused of political maneuvering and then ruled "out of court." It no longer matters that a brilliant case is presented for one's perspective. It need not be listened to if the field of play is defined as "political" rather than "intellectual."

The "Greater Moral Worth" Move.

In situations where a perspectival attack is defined as truly "political" (and not merely political), it is customary to shroud one's arguments in the cloak of "greater moral worth." This move invites combatants to malign each other's character and to minutely question a researcher's motivation for undertaking a given project. It is here that the great liberal defenders of the democratic faith will "defend to the death" the "right" of extremist, right-wing professors to malign the downtrodden, on the one hand, while calling into question the propriety and motivations of a homosexual sociologist who plans a study of the gay community, on the other. Questions concerning the value 
Mid-American Review of Sociology

orientation of various perspectives and projects are extremely important, but they must involve something more than a brawl over who is a "better" person if they are to be ethically responsible and intellectually engaging.

\section{The "Epistemological" Move.}

In this move, perspectival debates are "elevated" to the realm of "rational" discourse. The audience is assured that the discussion will be "value free" and "above personalities." When structured on dichotomous lines, the epistemological move runs roughshod over important axiological issues and forces the field of play onto a Procrustean bed where incompatible perspectives do not fit. (Ritzer's [1975] multiple paradigm trichotomy is not a substantial improvement in this regard.) A recent and exceptionally vicious example is provided by Mayhew's (1980) attempt to divide all of sociology into structuralist and nonstructuralist camps. His dichotomizing of sociology leads to a faulty conceptualization of both Marxism and structuralism and ultimately results in absurd, destructive comments such as: "structuralist sociologists view social psychology as the trained incapacity to comprehend the nature of social life" (Mayhew, 1980:357). The typical epistemological move in contemporary sociology forces debate over the "inherent correctness" of a given approach to knowledge and understanding. One is judged as either intellectually "right" or intellectually "wrong." Neither outcome is justified, of course, as there are no universal grounds on which to judge the specifically epistemological virtues of any of the current perspectives in sociology. The result is a parade of high sounding debates which appear to have intellectual content, but which are, in fact, bereft of both sound philosophy and responsible ethics. An essay such as Mayhew's is not a responsible intellectual discussion. Mayhew's case, at least, is a rear-guard ideological attempt to legitimate the authority of a sagging sociological elite.

Responsible ideological allegiance to a discipline requires that its supporters work for the immediate establishment of an emancipatory environment for their colleagues, students, and partners in the larger society.

Responsible epistemological/axiological discussions are virtually impossible in American sociology today. Responsible dialogue is
Epistemology, Axiology, and Ideology

replaced by destructive, dichotomizing debate which prevents emancipation from the hierarchical, patriarchal power structures of this society. Responsible emancipatory critique is suppressed by patriarchal power-wielders who control disciplinary structure, graduate departments, and mainstream journals. We must question this situation as we look forward to the close of the Twentieth Century. If we are to leave a responsible discipline to the next generation, we must today throw off the shackles of patriarchy and hierarchical oppression. If we are frustrated and defeated in this attempt, then we must move beyond the discipline to seek and support those few here and there who are working to establish a truly emancipatory sociology.

\section{CONCLUSION}

The foregoing presents a systematic program for responsible epistemology, axiology, and ideology in the social sciences. This program contains within it, however, a set of nested priorities. First, it is necessary to establish sociology as an emancipatory discipline. Without this initial step, responsible epistemological/axiological dialogue will be suppressed, discredited, and penalized. Attempts to voice responsible positions are thwarted through a variety of strategies. Thus, establishment of emancipatory environments for sociological discussion is the fundamental priority.

Second, we must turn to the axiological dimensions of our sociological activities. The social projects which meet the requirements of the highest axiological principles must be discovered and identified. Only then does it make sense to pursue our third priority: the explication and construction of knowledge-producing systems which will materially assist in the realization of responsible social projects.

We have spent too long pursuing these priorities in the wrong order. Our library shelves are filled with the records of epistemological debates in sociology. We find fewer volumes concerned with values and not a few of these are devoted to expunging "values" from the sociological lexicon. What few works we find concerning ideology, we are willing to footnote occasionally, but rarely as examples of legitimate sociological thought. It is time to turn the tide: ideology first, axiology second, epistemology third.

The author wishes to thank professors Mary Jo Deegan, Werner Leinfellner, and Helen Moore for their insights and criticisms during evolution of this paper. 


\section{REFERENCES}

Bach, E.

1965 "Structural Linguistics and the Philosophy of Science." Diogenes 15 (Fall):111-127

Buttimer, A.

1974 Values in Geography. Association of American Geographers, Commission on College Geography, Resource Paper No. 24. Washington, D.C.: Association of American Geographers.

Caws, P.

1967 Science and the Theory of Value. New York: Random House.

Creutz, A.

1981 "Social Access to the Professions: Late Nineteenth Century Academics at the University of Michigan as a Case Study." Journal of Social History 15(1):73-87.

Deegan,, M.J.

1980 "Feminist Sociology: A Revolution in the Sociology of Knowledge." Paper presented at the annual meetings of the Midwest Sociological Society, April 2-5.

1981 "Early Women Sociologists and the American Sociological Society: Patterns of Exclusion and Participation." The American Sociologist $16(1): 14-24$.

Eckhardt, W.

1973 "The Meanings of Values." Journal of Human Relations 21(1):54-80. Floistad, G.

1973 “Understanding Hermeneutics." Inquiry 16(4):445-465.

Friedrichs, R.W.

1970 A Sociology of Sociology. New York: The Free Press.

1973 "Phenomenology as a 'General Theory' of Social Action." Pp. 83-90 in E. Laszlo and J.B. Wilber (eds.), Value Theory in Philosophy and Social Science. New York: Gordon \& Breach Science Publishers.

Giorgi, A.

1975 Personal Communication, April.

Giorgo, A., W.F. Fischer, and R. Von Eckartsberg

1971 Duquesne Studies in Phenomenological Psychology, Vol. 1. Pittsburgh: Duquesne University Press.

Held, V

1970 "Can a Random Collection of Individuals Be Morally Responsible?" Journal of Philosophy 67(14):471-481.

Hill, M.R.

1977 “Axiological Dialogue in Geography." Antipode 9(2):93-96.

1981 "Positivism: A 'Hidden' Philosophy in Geography." Pp. 38-60 in M.E. Harvey and B.P. Holly (eds.), Themes in Geographic Thought. London: Croom Helm.

1983 "Class, Power, and Elites in the Academic Department." Unpublished paper, Department of Sociology, University of Nebraska-Lincoln.
Kuhn, T.S.

1970 The Structure of Scientific Revolutions (2nd edition, enlarged). Leinfellner, W. Chicago: University of Chicago Press.

1973 "Axiological Foundations of the Realising, the Technological, and the Cognitive Sciences." Journal of Human Relations 21(2):152-160.

1974 "A New Epitheoretical Analysis of Social Theories." Pp. 3-43 in W. Leinfellner and Kohler (eds.), Developments in the Methodology of Machan, T.R. Social Science. Dordrecht: D. Reidel.

1974 "Kuhn's Impossibility Proof and the Moral Element in Scientific Explanations." Theory and Decision 5(4):355-374.

Madsen, K.B.

1970 "The Languages of Science." Theory and Decision 1(2):138-154 Maglin, N.B.

1982 "The Demoralization Paper; or, Janet Mandelbaum, Jane Clifford, Anna Giardino, Zelda Campbell, Mira Ward, and Myself: The Fate of Six Eng lish Teachers." College English 44(6):575-582.

Mayhew, B.H

1980 "Structuralism Versus Individualism: Part 1, Shadowboxing in the Dark." Social Forces 59(2):335-375.

Menges, R.J. and W.H. Exum

1983 "Barriers to the Progress of Women and Minority Faculty." Journal of Higher Education 54(2):123-144.

Newman, J.

1982 "Academic Freedom and the Power of the Guild." Improving College and University Teaching 30(1):8-11

Parenti, M.

1980 "Political Bigotry in Academe." Chronicle of Higher Education 19(18):

Piaget, J.

1970 Structuralism. New York: Basic Books.

Radnitzky, G.

1973 Contemporary Schools of Metascience (3rd edition, revised). Chicago: Reynolds, P.D. Henry Regnery Company.

1982 Ethics and Social Science Research. Englewood Cliffs: Prentice-Hall Ritzer, G.

1975 Sociology: A Multiple Paradigm Science. Boston: Allyn and Bacon. Spiegelberg, $\mathrm{H}$

1971 The Phenomenological Movement: A Historical Introduction (2 vols.). The Hague: Martinus-Nijhoff 